\title{
Dördüncü Sanayi Devrimi'nin (Endüstri 4.0) Çalışma Hayatına ve İstihdama Muhtemel Etkileri ${ }^{1}$
}

\author{
DOI: $10.26466 /$ opus.479123
}

\author{
Hacı Yunus Taș \\ * Doç. Dr., Yalova Üniversitesi, İktisadi ve İdari Bilimler Fakültesi, Yalova/Türkiye \\ E-Posta: yunus.tas@yalova.edu.tr \\ ORCID: 0000-0003-3163-9416
}

\section{Öz}

Teknolojik gelişmeler her geçen gün hayatımızın bütün alanlarını etkilemeye devam etmektedir. 4. Sanayi Devrimi ile daha da hız kazanan yeni teknolojik gelişmeler her sanayi devriminde olduğu gibi 4. sanayi devriminin de çalışma hayatına, istihdama ve işsizliğge etkisi olacaktır. Diğer taraftan yeni işletmelerin, işkollarının ve yeni iş imkânlarının oluşumuna da katkı să̆laması beklenmektedir. İşletme sahibi girişimcilerin, yeni ve gelişen teknolojiye hem kendilerini hem de iş yerlerini hazırlamaları ve doğru üretim tarzların benimsemeleri için gerekli bilgilendirmenin uygun zamanda yapılması gerekir. Ayrıca, Iş̧letmelere varsa ihtiyaçlarımı karşılayacak gerekli desteklerin önceden verilerek işletmelerin yeni duruma hazırlanması kolaylaşacaktır. Her yeni teknoloji beraberinde bazı sektör ve iş alanların olumsuz etkileyerek işsizliğe neden olabilmektedir. Diğger taraftan da yeni sektörler ve mesleklerin ortaya çıkmasına vesile olarak istihdam artışını sağlayabilmektedir. Sonuç olarak; bir taraftan yeni teknoloji ve gelişmelerin ekonomiye ve sosyal hayata getirdikleri kolaylıklar, yüksek üretim ve verimlilikleri nedeniyle olumlu bakan işveren ve sermaye sahipleri olduğu gibi, diğer taraftan da işsizlik ve istihdam alanında sorun yaşayacaklarına inanan sendikalar ve işçi gruplarının yeni teknolojik gelişmelere olumsuz ve şüpheli bakmaları mümkündür. Bu iki durumda olağan bir durum olarak karşılanmalı ve bu duruma uygun çözümlerin topluma eş zamanlı olarak verilmesi oldukça önem kazanmaktadır. Bu çalışmamızda, teknolojik gelişmelerin aslında insan hayatında birçok kolaylık sağladığını, ancak işsizlik ve istihdam gibi bazı sorunları da beli bir süre beraberinde getirdiği anlatılacaktır. Ancak iyi bir planlama ve uygun programlarla bu olumsuz etkinin olumlu ve hatta avantaja yönlenebileceği vurgusu yapılacaktır. Her yeni teknolojik ve dijital gelişmenin yeni bir firsat olduğunu ve bu durumun toplumun tüm kesimlerine (esnaf, işçi, çiftçi) uygun bir şekilde anlatılması ve toplumun yeni duruma hazır hale getirilmesinin önemi konusunda bilgiler verilmeye çalışılacaktır.

Anahtar Kelimeler: Endüstri 4.0, İstihdam, Yenilik, Teknoloji, 4. Sanayi Devrimi

\footnotetext{
${ }^{1}$ Bu Makale, Ekim 2018, Uluslararası 2. Uluslararası GAP İsletme Bilimleri ve Ekonomi Kongresinde sunulan ve yayınlanan bildirim esas alınarak hazırlanmısțır.
}

OPUS (c) Uluslararası Toplum Araştırmaları Dergisi-International Journal of Society Researches ISSN:2528-9527 E-ISSN : 2528-9535

http://opusjournal.net 


\title{
The Possible Effects of the 4th Industrial Revolution on Working Life and Employment
}

\begin{abstract}
Technological developments continue to affect all areas of our lives with each passing day. As with every industrial revolution, the fourth industrial revolution will have an impact on working life, employment and unemployment. On the other hand, it is expected to contribute to the formation of new businesses, businesses and new job opportunities. It is necessary to inform the entrepreneurs, who are the business owners, in preparing the new and developing technology for themselves and their workplaces and to adopt the correct production styles at the appropriate time. In addition, the enterprises will be provided with the necessary support to meet the needs of the enterprises to prepare for the new situation will be easier. With each new technology, some sectors and business areas may adversely affect unemployment. On the other hand, it is possible to increase the employment as a result of the emergence of new sectors and professions. As a result; On the one hand, it is possible that the unions and workers groups who believe that they will have problems in the field of unemployment and employment, as well as employers and capital owners who are positively attracted by the new technologies and developments, the high production and efficiency they bring to economy and social life, and the negative and suspicious of the new technological developments. In these two cases, it should be met as an ordinary situation and it is very important that the appropriate solutions are given to the society simultaneously. In this study, it will be explained that technological developments provide many convenience in human life but some problems such as unemployment and employment bring along some time. However, it will be emphasized that this negative effect can be favorable and even advantageous with good planning and appropriate programs. Each new technological and digital development is a new opportunity, and all segments of the society (trades, workers, farmers) to be explained in a proper manner and the importance of making the community ready for the new situation will be given.
\end{abstract}

Keywords: Industry 4.0, Employment, Innovation, Entrepreneurship, Technology, 4th Industrial Revolution. 


\section{Giriş}

Günümüz dünyasında teknoloji, hayatımızın bir parçası olmaktan öte, hayatımızın kendisi konumuna gelmiş durumdadır. Gelişen teknolojiyle beraber en çok tartışma alanları haline gelen 3D yazılım, robotlar, yapay zeka gibi gelişmeler kendilerini Endüstri 4.0 başlığı altında göstermektedir. 4.Sanayi Devrimi'nin ne olduğunu daha iyi kavrayabilmek adına, günümüz üretim süreçlerine nasıl gelindiği ve süreçlerde işsizlik ve istihdam alanında yaşanan bazı olayların hatırlanması büyük önem arz etmektedir.

$\mathrm{Bu}$ anlamda tarihte bildiğimiz önemli bir teknolojik gelişme olan matbaanın bulunması ve Avrupa ülkelerinde 14. ve 15. Yüzyıllarda kullanılmasına rağmen Osmanlı Devletinde çeşitli sebeplerle 18.Yüzyılın başlarında kullanılmaya başlanmıştır. Aslında bilginin yayılması ve geleceğe aktarılması için önemli ve büyük kolaylıklar sağlayan bu teknolojinin Osmanlı devletine geç gelmesinin altında yatan birçok sebepten en önemlisi ise o dönem elle kitap ve belgeleri yazıp çoğaltan çok sayıdaki hattatların işlerini kaybetme, gelir düzeylerinin düşmesi ve itibarlarının azalacağı endişesi idi (Durmuş, 2017: 955 -956).

Sonraki dönemlerde arabaların ve yolların yapılması ile kervanciların, köprülerin yapılası ile sandal ve sal sahiplerinin, arabalarla yük taşınması ile hamalların benzer yeni teknolojik gelişme ile birlikte birçok meslek ve el sanatları ile uğraşanlar önceleri bu yenigelişmelere şiddetle karşı çıkmışlardı. Aslında hepsinin bu konudaki tepkisinin esas sebebi işsiz kalma ve toplumdaki eski nam ve saygınlıklarını kaybetme endişe ve korkusu idi.

Bu tür olumsuzluklar belli bir kesim için her zaman mümkün olabilmektedir. Bu nedenle konu ile ilgili önceden bazı tedbirler alınarak hem yeni duruma toplumun hazırlanması hem de muhtemel tepkiler ve kaygıların en az seviyede yaşanmasına engel olunabilir. Bu çalışmamızda yeni teknolojilerin 4. Sanayi devriminin (Endüstri 4.0) üretim ve hizmet sektörüne girmesiyle oluşabilecek olumlu gelişmelerin neler olabileceğinden bahsederken diğer taraftan da yeni gelişmelerden olumsuz etkilenebilecek kesimlere yönelik alınabilecek önlem ve tedbirlerin neler olabileceği ve nasıl alınacağı konusunda bilgiler paylaşılacaktır. 


\section{Sanayi Devirlerinin Tarihsel Gelişim Süreci}

Sanayi devriminin ilk olduğu dönem olan 18. YY sonları yani 1765'lerde buharın fabrikalarda kullanması ile başlamış olup, daha sonra 19. YY ortaları olan 1850'lerde elektriğin imalathane, atölye ve fabrikalarda kullanılmaya başlanması ile 2. Sanayi devrimi dönemi başlamıştır. 20. YY in ortalarında elektrikle çalışan hesap makinesinin icadıyla da 3. Sanayi dönem başlamıştı. 21. Yüzyıla gelindiğinde ise internet ve dijitalleşme ile nesnelerin üretime yön verdiği akıllı makine ve akıllı robotların dönemi olan 4.Sanayi Devrimi dönemi başlamış olmaktadır. Bu yeni dönem günümüzde Endüstri 4.0 dönemi olarak da adlandırılmaktadır. Ayrıca aşağıda dört sanayi dönemlerine ait kısa tarihi bilgiler verilecektir.

1-Birinci Sanayi Devrimi: Bu kapsamda endüstrileşmenin kısa tarihçesine baktığımızda Endüstri 4.0 öncesinde 3 farklı sanayi devriminin yaşandığ 1 ve bu sanayi devrimlerinden ilkinin çokta eski tarihli olmadığını görüyoruz. İlk olarak 1765'de James Watt'in Buhar Makinesini fabrikalarda Kullanmaya başlanmasıyla endüstrileşme sürecinin, Brinci Sanayi Devrimini başlattığını görüyoruz (Ege Bölgesi Sanayi Odası , 2015).

Şekil 1- Birinci. Sanayi Devrimi Aşamalan

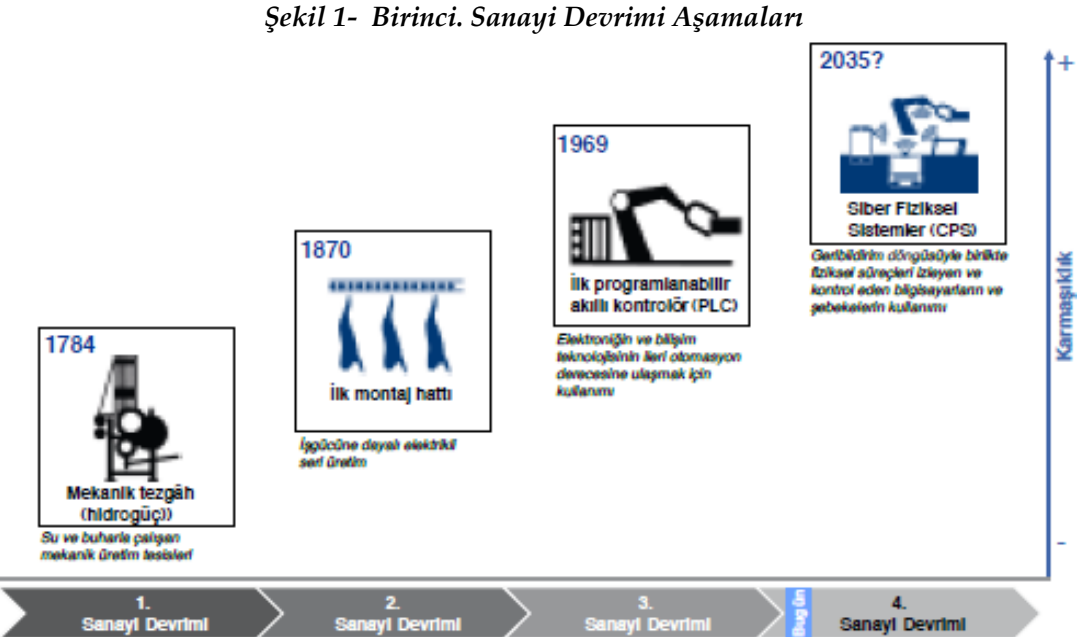

Kaynak: KPMG, 2015:1 https://home.kpmg.com/content/dam/kpmg/tr/pdf/ 2016/08 /tr-sanayi-4.PDF 
Bu kapsamda odunun yerine maden kömürünün ve buharın kullanılmas1 sonucunda iş ve hareket gücünün artırılması, makineleşmeyi ve üretimin daha çok fabrikalarda yapılması neticesini doğurdu. Klasik aile şirketleri ve küçük atölyeler, yerini daha ziyade fabrikalara bıraktı. Bu dönemde, buhar makinesinin bulunmasını çırçır makinesi (pamuğun büyük miktarda temizlenmesini sağlamaktadır), dikiş makinesi, uçak ve motorlu taşıt gibi teknolojiler izlemiştir.

Üretimdeki bu olumlu gelişmeler, ekonomik ve sosyal yapıyı etkilemiş ve Yaşanan bu gelişmeler neticesinde, nüfus artmış, ortalama hayatta kalma süresi uzamıştır (Ege Bölgesi Sanayi Odası , 2015). Birinci Endüstri Devrimi, dünyanın "daha küçük ve birbirine daha entegre" bir yer haline gelmesini sağlayan ilk ve önemli adımlarından biri olmuştur.

2- İkinci Sanayi Devrimi: Endüstrileşmenin ikinci aşaması 1850'lerde elektrik teknolojisinin, fabrika, atölye ve diğer üretim alanlarında, Buhar, kömür ve demirle birlikte çelik, elektrik, petrol ve kimyasal maddelerin de kullanılmasıyla olmuştur. Bunun neticesinde seri üretim başlamış, telefon, telgraf gibi iletişim araçlarının yanı sıra dayanıklı tüketim malları olan ürünler icat edilmiştir. Bu dönemde özellikle Henry Ford'un fabrikalarında kullanmış olduğu üretim tekniği olan, bant sistemi ve seri üretim teknikleriyle, otomobilin birçok ailenin hayatına girmesini sağlamış, ulaşımda ve iletişimde devrim denilebilecek büyük kolaylar sağlanmıştır. Birinci Endüstri Devrimi'nde hâkim olan demirin yerine çelik üretiminin gelişmesi, demir yolu taşımacılığını ve ticareti hızlandırmıştir.

Bütün bu gelişeler sonucunda, kentler hızla büyümeye başladı; gelişmiş ülkelerde ailelerin iş ve konaklama mekânları farklılaşmaya başladı. Hayat biçimleri büyük oranda değişti. . Ekonomik alanda yeni ve güçlü merkezi devletler kuruldu. Birinci Endüstri Devrimi'nde İngiltere ve Avrupa'da etkisini gösteren endüstrileşme, İkinci Endüstri Devrimi ile ABD, Japonya gibi ülkelerde de hızla yaygınlaşarak dünyada birçok bölge ve ülkeyi etkilemiştir.

3- Üçüncü Sanayi Devrimi: 2. sanayi devrimini 1950'lerde mekanik elektrik' le çalışan hesap makinesinin icadıyla 3. Sanayi devrimi izlemiştir. Bu dönemde de ilk küçük bilgisayar, cep telefonu, internet, hibrit 
otomobil insanların hayatına girmiş ve uzaya ilk defa mekik gönderilmiştir. Üretimde bilgisayar, iletişim ve ulaşım teknolojilerinden faydalanılması, günlük yaşamda çok daha küçük, pratik ve nano teknoloji ürünlerin de girmesine sebep olmuştur. Öyle ki; makineler, günlük yaşama da hâkim olmaya başlamış ve kas gücüne olan ihtiyaç giderek azalmıştır.

1970'lerden bugüne kadar süren döneme Üçüncü Endüstri Devrimi hâkim oldu. İkinci Dünya Savaşı sonrasında, elektronik, bilgi ve iletişim teknolojilerinin gelişmesiyle beraber üretimin otomasyonu sağlandı. Programlanabilir mantıksal denetleyici (PLC)'lerin gelişmesi sonucunda üretimde otomasyon ileri aşamalara taşınmaya başladı. İkinci Endüstri Devrimi üretimin serileşerek hızlanması olarak tanımlanırken, Üçüncü Endüstri Devrimi ise üretimin otomasyonu iletişim ve bilişim ve sayısallaşması olarak tanımlandı. Bu dönemde bilgisayar, mikro elektronik, fiber optik, lazer ve bilişim gibi teknolojilerin, telekomünikasyon, nükleer ve biyogenetik... vb. bilimlerin gelişimi üretimin yönünü etkiledi.

İletişim ve ulaşımdaki gelişmelerle, ticaret ve endüstri küresel hale geldi. Bu süreçte yaşanan en önemli gelişmelerden biri de dünya kaynaklarının hızla tükenmesi ve sürdürülebilirlik kavramının gündeme gelmesi oldu. Enerji kaynağı olarak Birinci Endüstri Devrimi'nde kömür, su ve buhar gücü; İkinci Endüstri Devrimi'nde ise petrol ve elektrik ön plandayken, Üçüncü Endüstri Devrimi'nde, ise çevresel kaygılarla güneş, rüzgâr gibi yenilenebilir enerji kaynakları ön plana çıkarak önem verilen enerji kaynakları olarak görüldü. Bütün bu gelişmelerin, daha önce mümkün olmayan yeniliklere imkân tanımasının yanı sıra, siberfiziksel sistemler, nesnelerin birbiri ile iletişime geçebilmesi (Nesnelerin İnterneti) gibi faktörlerin de etkisiyle, içinde bulunduğumuz Dördüncü Endüstri Devriminin başlamasına neden oldu.

4-Dördüncü Sanayi Devrimi (Endüdri 4.0): En nihayetinde 21.yüzylla gelindiğinde iletişim, bilgisayar ve internet teknolojilerinin birleşmesiyle beraber, 4. Sanayi devrimi olarak da adlandırılan Endüstri 4.0 gündemdeki yerini almıştır. Bu dönemde klasik emek faktörler olan kol ve kas gücüne olan ihtiyaç neredeyse tamamen ortadan kalkarak, makineler hem kendilerini ve hem de üretim süreçlerini yalnız başlarına yönetmeye başlamışlardır. 'Nesnelerin İnterneti' adı verilen yeni üretim sistemi ve bulut sistemi yaygınlaşmış, her makinenin 'akıllısı' hayatımızdaki 
yerini almıştır. Bütün bu sayılanlarla yetinilmemiş ve günümüzde bilgisayar teknolojileri ile zeki insanların bile yapamayacağı işler yaptırılabilir hale gelinmiştir. Ebetteki bu teknolojinin gelmiş olduğu son noktada değildir.

Yaşanan bu süreç ekonomide sosyal hayata, çalışma yaşamında, günlük işlerde yani hemen hayatın her alanında etkisini göstermiştir. $\mathrm{Bu}$ durum hem olumlu hem de olumsuz birçok sonuçlara neden olmuştur. Özellikle çalışma hayatına yönelik olarak oluşan negatif görüş ve bakış açıları olabildiği kadar, Endüstri 4.0 ile gelen teknolojinin üretimde bir çığır açacağı görüşleri de oldukça fazladır. Günümüzde gelişmek isteyen, ekonomik ve sosyal açıdan geri kalmak istemeyen tüm ülkelerin yeni sanayi devrimi olan Endüstri 4.0 in getirdiği yenilikleri takip etmesi ve bu teknolojiyi üretmesi bir zorunluluk haline gelmiştir.

\section{Dördüncü Sanayi Devrimini Oluşturan Temel Yapılar}

Nesnelerin İnterneti: Nesnelerin, interneti aracı olarak kullanmaları ile birbirleriyle iletişim içerisinde olmaları ve işleri kendi aralarında yönetmeleri durumudur. Yeni teknolojik yöntem ve sistem sayesinde üretim ve üretim süreci pratikleşecek, sipariş ve tedarik zinciri daha akıllı hale gelecek, enerji, altyapı ve personel maliyetleri azalacak, gelir ve kar düzeylerinde artış sağlanacaktır (http://www.endustri40.com/endustritarihine-kisa-bir-yolculuk).

Siber-Fiziksel Sistemler: Fiziksel dünya ile siber alanı internet ile birbirine bağlayan sistemlere siber-fiziksel sistemler (CPS-Cyber-Phsical System) adı verilmektedir. Sansürlerle desteklenmiş bu sistemler fiziksel dünyadaki hareketleri internet hizmetleriyle toplamakta ve global olarak nesnelerin etkileşimini içermektedir (Alçın, 2016).

Bir diğer şekliyle gözlemleme, koordinasyon ve kontrol gibi üretim süreçlerindeki temel prensiplerin, hesaplama ve iletişim bileşkesinden oluşan karma teknoloji tarafından yönetildiği sistemlerdir. Söz konusu karma teknoloji, fiziksel makineleri siber teknoloji ile bütünleştirme yoluyla dahada etkin hale getirmektedir (Ege Bölgesi Sanayi Odası , 2015).

$\mathrm{Bu}$ açıklama ve bilgilerden de anlaşılacağı gibi Endüstri 4.0 la birlikte, maliyetler düşerek, işletmelerin karlılık oranları artmakta ve artmaya da 
devam edecektir. Bu durum özellikle işletmeler için çok önemli bir hedef ve avantajdır. Diğger taraftan bu elde edilen kar ve kazançla birlikte işletmelerde çalışan işçilere daha az ihtiyaç olacak ya da daha hafif ancak bilgiye dayalı insan kaynağına ihtiyaç artacaktır.

Sosyal devlet ve sosyal girişimcilik açısından bu konuyu bir avantaja dönüştürmek elbetteki mümkün hale gelmektedir. Özellikle eğitim düzeyleri lise ve üstü dezavantajlı gruplar olan, gençler, kadınlar, engelli ve göçmenlerin bu alanda istihdam imkânları mümkün hale gelmektedir.

\section{Şekil.2- Endüstri 4.0 Durumunun Şekillerle Görünümü}

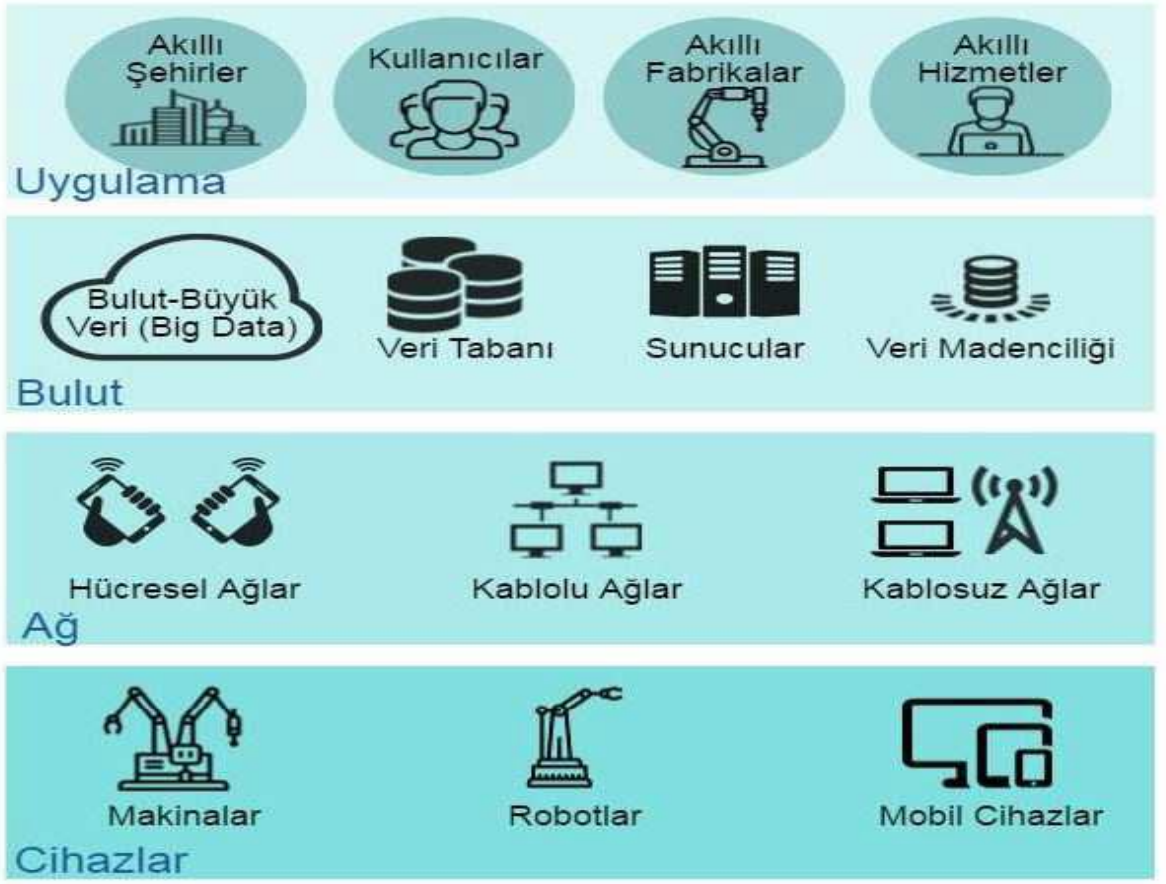

Kaynak: ALÇIN, Sinan (2016), "Üretim İçin Yeni Bir İzlek: Sanayi 4", Jurnal of life Economics, Volume 3 , Issue 2 , Jan 2016, s.23. 


\section{Endüstri 4.0' in Faydaları}

- Sistemin takibi kolaylaştığı için oluşabilecek arızaların tespiti de kolaylaşmıştır.

- Üretimde klasik üretim şekli ve anlayışı terk edilerek, müşteri tercih ve ihtiyacına yönelik müşteri odaklı daha esnek bir üretim tarzı benimsenmiştir.

- Hammadde, kaynak ve malzeme tüketimi azaldığından maliyetler de azalmış ve verimlilik artmıştır.

- Sistem çevreye dost olması ve kaynak tasarrufu sağlması ile yeşil enerji dönemine geçerek, sürdürülebilir olma imkanı artmaktadir.

- Üretim sisteminin kendisini yönetebilmesi ile üretim için gerekli olan diğer kaynaklara (insan, enerji makine gibi) ihtiyaç azalmakta, süreçleri robotlar yönettiği için hata payı düşmektedir.

- Değişen insan kaynakları yönetimi ile yeni hizmet ve iş modelleri geliştirilmektedir.

\section{Türkiye, 4. Endüstri Dönüşümünün Neresinde?}

Endüstri 4.0 ya da 4. Sanayi Devrimi, birçok çağdaş otomasyon sistemini, bilgi alışverişlerini ve üretim teknolojilerini kapsayan geniş ve ortak bir terim. Bu açıklamayla birlikte Türkiye bu kadar geniş kapsamlı olan ve günümüzde akıllı fabrika sisteminin oluşmasında önemli bir rol oynayan Endüstri 4.0 dönüşümünün neresinde yer alıyor. Bir taraftan yeni teknolojilerden uzak kalmadan öte yandan İstihdam alanında sorun yaşamamak için nasıl bir yol ve yöntem izlenebilir. Bu gibi konulara yönelik cevaplar verilmeye çalışılacaktır.

\subsection{Türkiye, Endüstri 4.0 dönüşümünün şu anda neresinde?}

Endüstri 4.0 dönüşümü uzun ve ince bir yol ve Türkiye henüz bu yolun başlarında bir yerde. Ülkemizin jeopolitik konumu ve düşük işgücü maliyeti gibi özelliklerinin artık küresel rekabetçilik açısından yeterli olmadığı bilinen ve sıkça dillendirilen bir gerçek. Dördüncü Sanayi devrimi ülkemizin rekabet kapasitesini daha üst düzeylere artırabilmek için 
önemli fırsatlar sunuyor. Ülkemizin bu alanda da en kısa zamanda hak ettiği yere gelebileceği tahmin edilmekle beraber, bunun kolay olmayacağı da ortadadır. Bunun için özel ve kamu sektör yöneticilerinin hem kendilerini hem de halkı bilgilendirip bu yeni hayata hazırlamaları gerekmektedir.

Ayrıca bu konuda istekli ve yeterli bilgi ve teknoloji ile donatılmış ne yaptığını ve ne istediğini bilen sağlam bir yapılanma ve organizasyona ihtiyaç vardır. Böyle bir irade ve istek Türkiye açısından süreci hızlandırıp kolaylaştırabilir. Yine bu alanda ciddi yatırım ve AR-Ge destekleri de gerektiğinde kesinlikle devlet gibi güçlü bir desteğin olması konunun olmazsa olmazlarındandır.

\subsection{Dördüncü Sanayii Devrimiyle birlikte Türkiye'de istihdam sorunu yaşanacak mi?}

Dördüncü sanayi devrimi de daha önceki endüstri devrimlerinde olduğu gibi toplam iş gücüne olan ihtiyacın azalmasından çok, açılacak yeni iş alanları ile kas gücüne dayalı işler yerine, daha nitelikli eğitim ve gelir düzeyi yüksek bir iş gücü potansiyeli yapısına geçilmesi beklenmektedir. Bu nedenle bu yeni teknolojik devrimden olumsuz olarak etkilenmemek için potansiyel iş gücünün, nitelik yönünden daha ileri düzeylere çıartılması zorunlu hale gelmiştir. Dolayısı ile işgücünün vasıf yapısının istenen düzeyde geliştirilmesini sağlayabilmek için eğitim ve istihdam politikalarını hızlı bir şekilde devreye alınmasına bağlıdır.

Endüstri 4.0 ülkemize piyasalarına tam olarak girmeden önce, akıllara ilk robotlar ve istihdam problemlerini getirdi. Aslında çok basit, insanların kas yapısını zorlayan işlerde çalışmak yerine daha çok bilgi, karar ve yön verme, yönetme ve sürekli uygulama-geliştirme yapacakları, bir iş modeli ile karşılaşacakları günler çok uzak görünmüyor. Bu günler hem çok yakın hem de çok uzak. Aslında bu yeni sanayi devriminde üretimde insanlar işlerini kaybetmeyecek, ancak iş tanımları ve meslekleri değişecektir. (https://www. endustri40.com/endustri-4.0da-insan). Ancak, yeni meslekler, yeni iş tanımları, yeni sektörler, yeni girişimler, yeni iş imkân ve fırsatlarını da beraberinde getirecektir.

Bahsedilen yeni işler ve yeni mesleklerin daha nitelikli ve tecrübeli çalışanlarla birlikte yürütülmesi, verimlilik açısından daha çok fayda sağ- 
layacaktır. Bu nedenlerden dolayı daha ileri yaşlarda bulunan işçilerin emekliliklerinin bir süre ertelemeleri ve daha uzun yıllar işgücü piyasalarında kalmaları öngörülmektedir (Bozlar,2018:63).

İstihdam konusundaki en önemli kaygılardan biri de, gelecekte robotların çalışan işçilerin yerini alabileceği ve işsizliğin artabileceği kaygısıdır. Bu konuda kesin bir cevap olmamakla birlikte, geçmiş sanayi devrimlerinin başında hep bu tür kaygılar yaşanmasına rağmen, her yeni teknolojik gelişmeler yeni iş alanlarının ve becerilerin gelişmesini de beraberinde getirdiğinden işsizliğin uzun vadede artması beklenmemektedir. Ancak, önemli iki sonucu kaçınılmaz olarak ortaya çıacaktır. Birincisi çalışma sürelerinin giderek kısalması ve ikinci olarak ta daha iyi bir iş ve kariyer sahibi olabilmek için yüksek vasıflar ve iyi bir eğitim gerektirmektedir.

Ayrıca, teknolojide meydana gelen hızlı değişiklikler ekonomik ve sosyal hayatta önemli değişikliklere neden olmakta ve toplumların üretim ve istihdam yapısını etkileyerek rekabet avantajını artırmaktadır. Bu bağlamda 4. Endüstri Devrimi ile birlikte kullanılabilen yüksek teknoloji imkânlarının da bu alanlarda faaliyet ve iş yapmak isteyen girişimcilerin ve KOBI' lerin işlerini kolaylaştıracağ 1 beklenmektedir (Açan, 2018: 188189).

Diğer taraftan yeni teknolojilerin sebep olacağı bazı olumsuzluklar olabileceği gibi birçok faydaları da olacaktır. Bunların en başında insan sağlığı için oldukça tehlikeli ve zararlı olan bazı iş kollarında (kimya, boya, iplik, maden ve inşaat) işçi yerine robotların çalıştırılması suretiyle insan sağlığının büyük oranda korunması sağlanacaktır. Bu şekilde boşa çıkan işçilerinde eğitilerek başka alalara kaydırılması mümkün olanlar istihdama kazandırılabilir, diğerlerine de ya tazminat ödenerek veya emekli edilerek çözümler bulunabileceği tahmin edilmektedir (Bozlar,2018:65).

\section{Endüstri 4.0’ da Olması Beklenen Yeni İş Kolları}

Burada bahsedilen 7 adet yeni iş kolu bulunmaktadır. Bunların birçoğu yurt dışında faaliyete başlamış olan bölümlerdir. Söz konusu iş kollarından bir kısmı mevcut ve piyasada var olsa da bunları Endüstri 4.0 için özelleşmiş yeni iş alanları olarak belirtmek lazım. Yeni iş kolu sayısı en 
az yedi olmasına karşın fikir vermesi için makalemizde kısa bilgiler verilecektir. Aklımıza gelen yada gelmeyen hemen her sektör, her iş alanı burada bahsedildiği gibi dijitalleşerek ve her biri ayrı birer iş kolu haline gelecektir (https://www. hightech-strategie.de.).

1. Endüstriyel Yazılım Programcıları: Bilişim sistemleri Endüstri 4.0'ın ana bileşenlerinden ve olmazsa olmazlarından ve programlama becerisi bütün diğer mesleklerin temel unsuru haline geldiği için yeni iş kolları arasında tekrar ye alabilmektedir. Ancak endüstriyel bileşenleri dikkate alındığında klasik programcılığa göre farklılıklar gösterebilmektedir (Sener ve Elevlı, (2017:29).

2. Bilişim Sistemleri ve Nesnelerin İnterneti Çözüm üreticisi: Veriyi değerleyip akıllı ve uygun tepkiler alabilmek için bu bilgilerin akıllı cihazlar arasında dağıtılabilmesi gerekiyor. Veri hızının iyi ve anlamlı bir şekilde yapılabilmesi için nesnelerin interneti dediğimiz işleme hâkim olacak yüksek vasıflı insanlara ihtiyaç vardır. (Sener ve Elevlı, (2017:30).

3. Endüstriyel Veri Analiz Uzmanı: Harvard Business Review, veri analiz uzmanlarını 21.yüzyılın en popüler meslek dalı olarak lanse etmiştir. Önümüzdeki dönemde tüm cihazların veri üreteceği beklenmektedir. Her tarafımızda olan verileri kayıt edilebilecek anlamlandırabilecek, ayıklayabilecek uzman kişilere çok ihtiyaç olacağından, bu meslekte önemli hale geliyor. (Sener ve Elevlı, 2017:29).

4. Robot Koordinatörü, Programcısı, Tamircisi: Robotik makinalar üretim alanındaki ana cihazlarımız olacak. Üretimde oluşabilecek hataları en az seviyelere indiren, durmadan $7 / 24$ çalışabilen, vasıfsız iş gücünü tamamlayan ana makinalar olacaklardır..

5. Üretim Teknolojileri Uzmanı : Endüstri 4.0 kurucu ve önde gelen ülkesi olan Almanya hükümeti tarafından 2008 yılından itibaren resmi bir iş pozisyonu olarak kabul edilen bu mesleğin eğitim süresi 3 yıl olarak belirlenmiştir. Üretim süreçlerini planlayıp ihtiyaç duyulan makina ve tezgâhları tespit eder ve bunların programlanmasını sağlarlar. 
6. Akıll Şehirler Planlayıcılar (Smart City Planner): Üretim süreçleri ve ürünler akıllanırken elbette açığa çıkn ürünler de o süreçlere uyumlu olmalıdır. Dolayısı ile trafik lambaları gelen araçları okuyabilecek, ambulans gibi acil durum vakası söz konusu ile ana merkeze gelen verileri hesaplayıp yolların ambulanslar için açı hale gelmesini sağlayacaktır. Binalar bu süreçte en az kendi ihtiyaçları kadar enerji üretir hale gelecektir. Bir alanda fazla üretilen enerji diğer tarafa otomatik olarak aktarılacaktır.

7. Ürün Tasarımcısı ve Üreticiler: Üç boyutlu yazıcıların üretime geçmeleri ile aklımıza gelen her ürünü tasarlayarak ve bunu 3B yazıcılar için hazır hale getirebilmek yeni üretim alanında tek başına bir devrim olmaktadır. Bir terzinin ölçü alıp kıyafet dikebilmesi için kişiye özel tasarım yapabilen üreticiler ortaya çıkacaktır (Sener ve Elevlı, (2017:29).

Yukarıda sayılan yeni meslek alanları, Dördüncü Sanayi Devrinde ortaya çıkan ve gelişen yeni iş alanlarının temel taşlarını oluşturacaklardır. $\mathrm{Bu}$ mesleklerinde bir çok alt kollarının da zamanla oluşacağ edilmektedir. $\mathrm{Bu}$ anlamda yeni sanayi devrimiyle bazı meslekler son bulurken yeni ve yüksek bilgi ve teknoloji gerektiren meslekler ortaya çıkacaktır. Yani bir taraftan işsizliğin artması beklenirken diğer taraftan da yeni iş $\mathrm{v}$ meslek alanları ile istihdamın artması sağlanacaktır. Bu yeni dönemde teknolojiye geliştiren ve kullanan ilk ülkeler de işsizliğin artmasından ziyade azalması beklenirken, diğer taraftan teknolojiyi kullanamayan ve bu alanda geç kalan ülkelerde işsizlik sorunu yaşanabileceği tahmin edilmektedir.

\section{Endüstri 4.0 Bağlamında Girişimcilikte Yeni Yaklaşımlar Ve Fırsat- lar}

Endüstri 4.0 uygulamalarının önemli beklentilerinden biri yeni hizmet ve iş modellerinin geliştirilmesi ve buna bağlı olarak yeni işletme girişim türlerinin ortaya çıkacak olmasıdır. Nitekim bu konuda önemli gelişmeler yaşanmaktadır. İş modeli bir işletmenin nasıl yeni değerler üretebildiğinin, bunları pazar ve müşteriye nasıl ulaştırdığının ve en nihayetinde nasıl gelir elde ettiğinin hikâyesidir Endüstri 4.0 uygulamaları aynı 
zamanda kendisiyle beraber yeni iş imkan ve modellerini de gündeme getirmektedir.

Endüstri 4.0'1n, işlerin oluş süreçlerini esastan etkileyen sanal bir ortamda, nesnelerde bulunan bir çip vasıtasıyla internet tekniği ile birbirlerine bilgi taşımaları (nesnelerin interneti), üç boyutlu yazıcılar gibi büyük teknolojileri, temel verilerle birlikte dijital entegrasyon ve veri odaklı hizmetler için yeni fırsatlar oluşturma ve yeni bilgiler etrafında hayal edilemeyecek kadar yeni iş modelleri ortaya çıkmaktadır (Soylu, 2018: 50 ).

Yeni ticari modeller, entegrasyon ve yeni hizmetler etrafında çözümler sunmakta ve şirketleri bu yükselen değerler doğrultusunda biçimlenmektedirler. Bu bağlamdaki veriler, operasyonel etkinlikle ilişkili olmaktan çok, değer üretmek için yetki verilmiş birer varlık olarak görülmektedir.

Yeni Girişimciliğin Kodlarn: Endüstri 4.0'ın şirketlerden ilk olarak beklediği ve olmazsa olmazı olan temel strateji, İnovasyon, değişim yeteneği, hız ve çevikliktir. Üçüncü sanayi devrimini belirlemiş olan basit dijitalleşme, yerini çok çeşitli teknolojilerin yeni ve farklı biçimlerde bir araya getirilmesi olarak yükselen çok daha karmaşık İnovasyon biçimleri şeklinde olmaktadır. Bu durum şirketlerin yeni iş yapma tarzlarını gözden geçirmeye zorlamakta ve mevcut işlerini daha da geliştirmek ve çeşitlendirmeye zorlamaktadır.

Her Yeni sanayi devrimi döneminde işgücü açısından baktığımızda; iki temel sonuç ortaya çıkmaktadır. Bunlardan birincisi çalışma sürelerinde kısmen azalma olmaktadır. İkinci önemli sonucu ise kariyer ve iyi bir işe sahip olabilmek için daha yüksek vasıflar gerektiğidir.

\section{Sonuç}

Çalışmada örnekleri verilen sosyal girişimler gibi teknoloji kullanılarak toplum faydasını maksimuma çıkarmayı hedefleyen projeler her geçen gün hem sayı olarak hem de görünürlük olarak artış sağlamaktadır. Özellikle sosyal medyanın da etkisiyle üretilen bu sosyal değerler birçok ihtiyaç sahibi tarafından kullanılmakta ve hayatları kolaylaştırmaya devam etmektedir. 
Teknolojinin beraberinde getirmiş olduğu bazı olumsuz yönleri olsa da, ülkelerin, toplumların ve hatta bireylerin teknolojiden kaçınması çoğu zaman mümkün olmamaktadır. Bu yüzden teknoloji desteğiyle üretilen katma değerin sosyal alanlarda kullanılarak topluma bir faydasının olması amacıyla hareket edilmeli ve bu tarz girişimler desteklenmelidir. Bu şekilde bilinçli yapılacak olan yatırım ve üretimlerden başta devletler ve firmalar olmak üzere her kesimin olumlu bir şekilde istifade etmesi beklenmektedir. Ülkesi ve işletmeleri zengin olan demokratik toplumlarda bireylerin bu zenginlikten pay almamaları düşünülemez. Dolayısı ile bireylerde refah içinde olacaklardır.

4. sanayi devrimi de daha önceki endüstri devrimlerinde olduğu gibi toplam işgücü ihtiyacının azalmasından çok, açlacak yeni iş alanları ile bilgi düzeyi düşük işlerden çok daha nitelikli, eğitim ve gelir düzeyi yüksek bir iş gücü potansiyeli yapısına geçilmesini gerektirecektir. Bu nedenle bu yeni teknolojik devrimden olumsuz olarak etkilenmemek için potansiyel iş gücünün, nitelik yönünden daha ileri düzeylere çıartılması zorunlu hale gelmiştir. Dolayısı ile işgücünün vasıf yapısında istenen oranlarda geliştirmeyi sağlayacak eğitim ve istihdam politikalarını ne kadar hızlı ve başarı ile devreye alabileceğine bağlı.

Endüstri 4.0 ülkemize piyasalarına tam olarak girmeden, akıllara ilk önce robotlar ve istihdam problemlerini getirdi. Aslında çok basit, insanların kas yapısını zorlayan işlerde çalışmak yerine daha çok bilgi, karar verme, yön vereme, yönetme ve sürekli uygulama-geliştirme yapacakları, bir iş modeli ile karşılaşacakları günler çok uzak görünmüyor. Bu günler hem çok yakın hem de çok uzak. Aslında bu yeni sanayi devriminde üretimde insanlar işlerini kaybetmeyecek, ancak iş tanımları ve meslekleri değişecektir.

Ayrıca bir çok genç ve yetenekli beyinlerin ülkelerine ve insanlığa faydalı işler yapma isteklerini, yeni teknolojik üretim alanlarına yönlendirilerek, ileri düzeyde teknoloji kullanabilen girişim, işletme ve kurumlarının hayata geçirilebileceğinden şüphemiz yoktur. Bu tür işletmelerin çoğalması ile hem üretim hem de istihdamın artışı sağlanabilecektir. Bu nedenle zaman kaybetmeden ülke ve devlet olarak 4. Sanayi devriminin kodlarını iyi bir şekilde analiz ederek toplumumuza en faydalı şekilde kullanmak durumundayız. Aksi durumda teknolojiyi başkaları kullanırken işsizliği biz yaşayabiliriz. 


\title{
EXTENDED ABSTRACT
}

\section{The Possible Effects of the 4th Industrial Revolution on Working Life and Employment}

\author{
Hacı Yunus Taş \\ Yalova University
}

Technological developments continue to affect all areas of our lives with each passing day. As with every industrial revolution, the fourth industrial revolution will have an impact on working life, employment and unemployment. On the other hand, it is expected to contribute to the formation of new businesses, businesses and new job opportunities. For this reason, it is very important that educational policies (primary school, university) are reviewed according to this new situation and planned in accordance with technological developments.

In this sense, the education policies implemented in the classical education system to make it suitable for the future. the new education system needs to be revised in accordance with the digital world and markets. Likewise, in high school and university graduates who have completed their education, they will be able to follow new technological developments actively outside their education life and allow them to prepare for their future careers in this way and they will have lower rates of employment and unemployment in the new period.

It is necessary to inform the entrepreneurs, who are the business owners, in preparing the new and developing technology for themselves and their workplaces and to adopt the correct production styles at the appropriate time. In addition, the enterprises will be provided with the necessary support to meet the needs of the enterprises to prepare for the new situation will be easier. With each new technology, some sectors and business areas may adversely affect unemployment.

Forthere more, it is possible to increase the employment as a result of the emergence of new sectors and professions. As a result; On the one hand, it is possible that the unions and workers groups who believe that 
they will have problems in the field of unemployment and employment, as well as employers and capital owners who are positively attracted by the new technologies and developments, the high production and efficiency they bring to economy and social life, and the negative and suspicious of the new technological developments. In these two cases, it should be met as an ordinary situation and it is very important that the appropriate solutions are given to the society simultaneously.

Industry 4.0 introduced robots and employment problems to the minds before they entered our country fully. In fact, it is very simple, instead of people who work on the muscle structure of the work more information, decision-making, orientation, management and continuous application-development will do, the days when they will encounter a business model does not seem too far. These days are both very close and far away. In fact, in this new industrial revolution, people in production will not lose their jobs, but job descriptions and professions will change.

In addition, there is no doubt that many young and talented minds can be put into practice in order to make their businesses and institutions capable of using technology at the provincial level by directing their requests to their country and humanity to do useful works and to new technological production areas. With the increase of such enterprises, both production and employment will be increased. Therefore, as a country and a state without losing time, we have to analyze the codes of the 4th Industrial Revolution in a good way and use it in the most beneficial way to our society. Otherwise, we can experience the negative effects of unemployment while others are using technology.

On the other hand, there will be some disadvantages caused by new technologies and they will have many benefits. In the beginning of these, human health will be protected in some sectors which are very dangerous and harmful for human health (chemical, paint, yarn, mine and construction) by employing robots instead of workers. In this way, those who are wasted in their workers can be transferred to other areas, those who are able to be transferred to employment, others are paid or retired compensation is expected to be found.

In this study, it will be explained that technological developments provide many convenience in human life but some problems such as 
unemployment and employment bring along some time. However, it will be emphasized that this negative effect can be favorable and even advantageous with good planning and appropriate programs. Each new technological and digital development is a new opportunity, and all segments of the society (trades, workers, farmers) to be explained in a proper manner and the importance of making the community ready for the new situation will be given.

\section{Kaynakça/References}

Açan, B. (2018), Müşteri Odaklı Anlayış: KOBİ'ler Üzerine Pilot Bir Araştırma, ( Editör: S. Batal). Sosyal Bilimlerde Alternatif Yorumlar içinde (S. 187-216). İstanbul: Gece Kitaplığı.

Alçın, S. (2016). Üretim için yeni bir izlek: Sanayi 4.0. Journal of life Economics, 3(2), $19-30$.

Bosca, N. (2017, 01 29). Endüstri 4.0: Bugüne Kadar Geçen Süreç. Nazmi Bosca Web Sitesi: https://nazmibosca.com/2017/01/29/endustri-40-bugune-kadar-gecen-surec/ Erişim Tarihi: 11.10.2018.

Bozlar, T. (2018). 4. sanayi devriminin işgücü piyasasına olası etkileri. İ̧KUR, İstihdamda 3İ Dergisi, 27, 62-67.

Bulut, E. ve Akçacı, T. (2017). Endüstri 4.0 ve inovasyon göstergeleri kapsamında türkiye analizi. Assam Uluslararası Hakemli Dergi, 7, 50-72.

Çiçek, B. (2017). Scode'un genç girişimcisi Kadir Can Kırkoyun ile röportaj. Pazarlama Türkiye: https://pazarlamaturkiye.com/roportajlar/scodeun-genc-girisimcisi-kadir-can-kirkoyun-ile-roportaj-yaptik/ , Erişim Tarihi:_15.09.2018.

Durmuş, B. T. (2017). Matbaa teknolojisinin Osmanlı devletine giriş koşulları ve tartışmalar. Gümüşhane Üniversitesi İletişim Fakültesi Elektronik Dergisi, 5(2), 950-968

Ege Bölgesi Sanayi Odası . (2015). Endüstri 4.0. İzmir: Ege Bölgesi Sanayi Odası Araştırma Müdürlüğü.

Evreka (2015). Evreka nedir? Evreka: http://evreka.co/tr/nedir/ , Erişim Tarihi:_15.09.2018. 
Fazla Gida, (2015). Hikayemiz: Fazla G1da. https://www.fazlagida.com/hakkimizda/ Erişim Tarihi:_15.09.2018.

Güler ,B. K. (2011). Yoksullukla mücadelede sosyal girişimcilik: Ashoka üyelerinden sosyal yenilikçi örnek uygulamalar. Dokuz Eylül Üniversitesi, Sosyal Bilimler Enstitüsü Dergisi, 13(3), 79-111

http://www.siemens.com/innovation/en/home/pictures-of-the-future/digitalization-andsoftware/simulation-and-virtual-realitytrends.html, Erişim Tarihi:_15.10.2018.

http://www.siemens.com/innovation/en/home/pictures-of-the-future/digitalizationandsoftware/simulation-and-virtual-realityservice.html, Erişim Tarihi:_15.08.2018.

Aytuğ, H. K. (2011). Küresel rekabetin işletmelerin üretim ve istihdam yapısı üzerindeki etkileri. Akademik Yaklaşımlar Dergisi, 2(2), 45-77

Kodluyoruz. (2017). Biz Kimiz: Kodluyoruz. Kodluyoruz Web Sitesi: http://www.kodluyoruz.org/bizkimiz/ , Erişim Tarihi:_15.09.2018.

OTSIMO. (2017). Otsimo. https://otsimo.com/tr/ , Erişim Tarihi: 15.09.2018.

Selek, A. Endüstri Tarihine Kısa Bir Yolculuk. Türkiye'nin Endüstri 4.0 Platformu:http://www.endustri40.com/endustri-tarihine-kisa-biryolculuk, Erişim Tarihi:_15.08.2018.

https://www. endustri40.com/endustri-4.0da-insan-robot-ve-istihdam/, Erişim Tarihi: 14.10 .2018

SIEMENS, Türkiyenin Endüstri 4.0 Platformu Yeni Devrim, Endüstri 4.0 Yolunda, E Dergi http://www.siemens.com.tr/dijitalfabrikalar, Erişim Tarihi:_15.10.2018.

Soylu, A. (2018). Endüstri 4.0 ve girişimcilikte yeni yaklaşımlar. Pamukkale Üniversitesi Sosyal Bililmler Enstitüsü Dergisi, 32, 43-57.

Sener S. ve Elevlı B., (2017) Endüstri 4.0'da yeni iş kolları ve yüksek öğrenim. Mühendis Beyinler Dergisi 1(2), 25-37

Taş, H.Y., Küçükoğlu M, Özcan, Selami (2016). Osmanlıdan günümüze sosyal girişimcilik örnekleri ve topluma kazandırdıkları. 2. Uluslararası Çin'den Adriyatik'e Sosyal Bilimler Kongresi Kongre Kitabı, 258-266. 
Taş, H. Yunus, Demirdöğmez M. ve Küçükoğlu, M., (2018). Endüstri 4.0' in çalışma hayatına ve girişimciliğe muhtemel etkileri. 2. Uluslararası Gap İsletme Bilimleri ve Ekonomi Kongresi, 4-7 Ekim, 2018, Ss.94-104- 6

Vural, Y. (2018). Yeni nesil sosyal girişimcilik. MAGG4: https://magg4. com/yeni-nesil-sosyal-girisimcilik/ , Erişim Tarihi:_15.09.2018.

\section{Kaynakça Bilgisi / Citation Information}

Taş., H. Y. (2018). Dördüncü sanayi devrimi'nin (Endüstri 4.0) çalışma hayatına ve istihdama muhtemel etkileri. OPUS-Uluslararası Toplum Araştırmaları Dergisi, 9(16), 1817-1836. DOI: 10.26466/opus.479123 